\title{
TESCHKE, Benno, Mythos 1648. Klassen, Geopolitik und die Entstehung des europäischen Staatensystems
}

\section{Claire Gantet}

\section{OpenEdition}

\section{Journals}

Édition électronique

URL : http://journals.openedition.org/ifha/1787

DOI : $10.4000 /$ ifha. 1787

ISSN : 2198-8943

\section{Éditeur}

IFRA - Institut franco-allemand (sciences historiques et sociales)

Référence électronique

Claire Gantet, «TESCHKE, Benno, Mythos 1648. Klassen, Geopolitik und die Entstehung des europäischen Staatensystems », Revue de l'IFHA [En ligne], Date de recension, mis en ligne le 01 janvier 2009, consulté le 22 septembre 2020. URL : http://journals.openedition.org/ifha/1787 ; DOI : https://doi.org/ 10.4000/ifha. 1787

Ce document a été généré automatiquement le 22 septembre 2020.

(C)IFHA 


\title{
TESCHKE, Benno, Mythos 1648. Klassen, Geopolitik und die Entstehung des europäischen Staatensystems
}

\author{
Claire Gantet
}

1 Pour le lecteur allemand, confronté à la revalorisation très forte de la paix de Westphalie comme loi d'Empire et sa relativisation dans l'histoire des relations internationales depuis les grandes expositions de Münster et Osnabrück en 1998, et pour le lecteur français versé dans les sciences politiques et l'interprétation, par Bertrand Badie, des traités de 1648 comme d'un « tournant westphalien » marquant le début de relations internationales sécularisées, fondées sur les notions de droit des gens et de souveraineté, le livre de B.T. est assurément dépaysant. Issu d'une thèse soutenue au Département des relations internationales de la London School of Economics and Political Science, ce livre prend acte des incertitudes sur l'ordre actuel du monde - que celui-ci relève de la globalisation, d'une gouvernance globale, d'une société civile globale ou d'autres principes - pour déconstruire l'événement fondateur (ou du moins tenu pour tel dans les sciences politiques) du monde dans lequel nous vivons : la paix de Westphalie. Opposé tant aux théories « néo-réalistes » ahistoriques, à la sociologie historique wébérienne qu'au marxisme classique, B.T. souligne que les relations internationales sont fondées, avant comme après 1648 , sur des contacts et conflits personnels, dynastiques. Mais l'ambition de B.T. va au-delà. Il veut reconstruire et théoriser la genèse et le développement du système européen, de l'Empire carolingien à l'époque moderne. À cette fin, il s'appuie sur le " marxisme politique " défini par Robert Brenner, qui fait des conflits pour la propriété des biens la dynamique majeure de l'évolution historique.

2 La géopolitique du haut Moyen Âge est pour B.T. déterminée par l'accumulation de la plus-value paysanne par le pouvoir politique et militaire. Les conflits de classes mènent à une concentration croissante des moyens de contrainte et d'expansion territoriale. Il n'existe pas plus de distinction entre la politique intérieure et la politique extérieure qu'entre l'économie et la politique. À partir du XIIe s., des États dynastiques 
s'établissent au gré de liens féodaux personnels; à la fin du Moyen Âge, une différenciation entre les affaires extérieures et les affaires intérieures s'esquisse. À la différence de la plupart des politologues, B.T. interprète la " crise du XIVe siècle " comme le début, non de la formation des États modernes, mais de deux lignes d'évolution, qu'il esquisse d'après les exemples français et anglais. En conséquence de la concentration politique à partir de 1066 et des conflits de classe, un État moderne, fondé sur une économie agraire capitaliste se forme tôt en Angleterre. En France en revanche, la fragmentation de la seigneurie permet certes aux paysans de se libérer du servage, mais elle laisse libre cours à la centralisation des pouvoirs politiques et à l'aggravation des prélèvements fiscaux - bref, à la formation de l'État absolutiste. Ce n'est donc qu'en Angleterre que le capitalisme et l'État moderne se développent de pair. Le capitalisme est reçu différemment dans les autres pays, selon les conflits de classe qui les habitent, bien après 1648 .

3 Bien des aspects de ce livre sont assez étrangers à l'historien, à commencer par la démarche qui consiste à sélectionner un élément, ici le capitalisme ou le modèle anglais, pour en faire le facteur déterminant du développement historique, là où l'historien est attaché à fonder son raisonnement sur la pluralité des sources et des grilles d'interprétation. L'historien ne peut aussi que noter au fil des pages une série d'erreurs factuelles et d'interprétations erronées ou très datées. D'un point de vue historiographique toutefois, par le renouveau du marxisme dont il témoigne, ce livre est intéressant.

Claire GANTET (Université Paris I - Freie Universität Berlin) 